Check for updates

Cite this: RSC Adv., 2018, 8, 27686

\title{
Efficient $\left(\mathrm{Cu}_{1-x} \mathrm{Ag}_{x}\right)_{2} \mathrm{ZnSn}(\mathrm{S}, \mathrm{Se})_{4}$ solar cells on flexible Mo foils
}

\author{
Xue Yu, (D) a Shuying Cheng, ${ }^{\text {ab }}$ Qiong Yan, ${ }^{a}$ Jinling Yu, ${ }^{\text {ab }}$ Wen Qiu, ${ }^{a}$ Zhengji Zhou, ${ }^{c}$
} Qiao Zheng ${ }^{\mathrm{ab}}$ and Sixin Wu*

Cation substitution plays a crucial role in improving the efficiency of $\mathrm{Cu}_{2} \mathrm{ZnSn}(\mathrm{S}, \mathrm{Se})_{4}(\mathrm{CZTSSe})$ solar cells. In this work, we report a significant efficiency enhancement of flexible CZTSSe solar cells on Mo foils by partial substitution of $\mathrm{Cu}^{+}$with $\mathrm{Ag}^{+}$. It is found that the band gap $\left(E_{\mathrm{g}}\right)$ of $\left(\mathrm{Cu}_{1-x} \mathrm{Ag}_{x}\right)_{2} \mathrm{ZnSn}(\mathrm{S}, \mathrm{Se})_{4}(\mathrm{CAZTSSe})$ thin films can be adjusted by doping with Ag with $x$ from 0 to $6 \%$, and the minimum $E_{g}$ is achieved with $x=5 \%$. We also found that Ag doping can obviously increase the average grain size of the CAZTSSe absorber from 0.4 to 1.1 $\mu \mathrm{m}$. Additionally, the depletion width $\left(W_{d}\right)$ at the heterojunction interface of CAZTSSe/CdS is found to be improved. As a result, the open-circuit voltage deficit $\left(V_{\text {oc,def }}\right)$ is gradually decreased, and the band tailing is suppressed. Benefiting from the enhanced open-circuit voltage $\left(V_{o c}\right)$, the power conversion efficiency (PCE) is successfully enhanced from $4.34 \%(x=0)$ to $6.24 \%(x=4 \%)$, and the $V_{\text {oc,def }}$ decreases from 915 to $848 \mathrm{mV}$.

rsc.li/rsc-advances

Ag substitution is a promising approach to reduce the anti-

\section{Introduction}

Thin film solar cells based on kesterite materials of CZTSSe have gained increasing attention over the past few years due to their scalable cell efficiency and nontoxic earth-abundant components. ${ }^{1-6}$ The CZTSSe solar cells on classical rigid soda glass (SLG) substrates have made good progress, with the highest PCE of $12.6 \%$ for the CZTSSe solar cells demonstrated by IBM. ${ }^{7}$ However, the efficiency of the CZTSSe solar cells on flexible substrates (with a PCE of 6.9\%) is still lower than those on SLG substrates. ${ }^{8}$ Compared with the rigid substrates, the flexible substrates have the advantages of high temperature resistance, good mechanical strength, and a compatible coefficient of linear thermal expansion especially for Mo foil. ${ }^{9-12}$ Due to cost-effective roll-to-roll processes, flexible PV devices are more attractive for their potential applications in both ground and space. For CZTSSe devices based on either rigid glass substrates or flexible substrates, the current bottleneck is the high $V_{\text {oc,def }}$, which is due to the quantity of $\mathrm{Cu}_{\mathrm{Zn}}$ antisite acceptor defects and band tailing caused by $\mathrm{Cu} / \mathrm{Zn}$ disorder. Thus, it is crucial to reduce the $\mathrm{Cu}_{\mathrm{Zn}}$ antisite defects and suppress $\mathrm{Cu} / \mathrm{Zn}$ disorder. ${ }^{13-16}$

${ }^{a}$ College of Physics and Information Engineering, Institute of Micro-Nano Devices and Solar Cells, Fuzhou University, Fuzhou, 350108, P. R. China. E-mail: sycheng@fzu. edu.cn

bJiangsu Collaborative Innovation Center of Photovolatic Science and Engineering, Changzhou, 213164, P. R. China

'The Key Laboratory for Special Functional Materials of MOE, Collaborative Innovation Center of Nano Functional Materials and Applications, Henan University, Kaifeng, Henan 475004, P. R. China. E-mail: wusixin@henu.edu.cn site defect density and band tailing by replacing $\mathrm{Cu}$ in the lattice. ${ }^{17}$ Theoretical calculation demonstrated that the radius of $\mathrm{Ag}^{+}(1.14 \AA)$ is substantially larger than that of $\mathrm{Cu}^{+}(0.74 \AA)$ or $\mathrm{Zn}^{2+}(0.74 \AA) .{ }^{15}$ And the formation energy of $\mathrm{Ag}_{\mathrm{Zn}}$ defect (at $0.2 \mathrm{eV}$ above the valence band edge) is much larger than that of the $\mathrm{Cu}_{\mathrm{Zn}}$ defect $(0.12 \mathrm{eV}) .{ }^{16}$ There are several experimental studies reported the positive effects of the substitution of $\mathrm{Cu}$ by Ag on rigid glass substrates. Gershon et al. reported that the efficiency of Ag-substituted CAZTSSe devices can be enhanced dramatically to $10.2 \% .^{17}$ Hages et al. prepared CAZTSSe absorbers through sulfide nanocrystal inks, and the device efficiency was increased to $7.2 \% .{ }^{18} \mathrm{Wu}$ et al. reported that partial substitution of $\mathrm{Cu}^{+}$with $\mathrm{Ag}^{+}$can reduce the $V_{\text {oc,def }}$ of CZTSSe solar cells with an efficiency of $10.36 \% .{ }^{19}$ Zhao et al. reported the CAZTSSe solar cells with an efficiency of $7.12 \%$ and about a $30 \mathrm{mV} V_{\text {oc,def }}$ achieved by Ag incoporation though DMSO method. ${ }^{20}$ However, all the experimental researches on $\mathrm{Ag}_{2}$ $\mathrm{ZnSnS}_{4}, \mathrm{Ag}_{2} \mathrm{ZnSn}(\mathrm{S}, \mathrm{Se})_{4}$ or CAZTSSe were on SLG substrates. Efficient $\mathrm{Ag}$ substitution for the CZTSSe device on flexible substrate to alleviate the $V_{\mathrm{oc} \text {,def }}$ and to improve flexible PV device performance has not been reported.

In this work, we fabricated CZTSSe thin films with partially substituting $\mathrm{Cu}^{+}$with $\mathrm{Ag}^{+}$on Mo foils by an elemental precursor solution-process. A device with the structure of Mo foil/ CAZTSSe/CdS/i-ZnO/ITO/Ag was prepared and its efficiency was $6.24 \%$ based on $0.21 \mathrm{~cm}^{2}$. We systematically studied the effect of Ag doping on flexible CZTSSe thin films solar cells. By doping Ag, not only the $E_{\mathrm{g}}$ of CZTSSe thin films can be adjusted, but also the $W_{\mathrm{d}}$ at the heterojunction interface of CZTSSe/CdS can be improved, especially at the optimal $\mathrm{Ag} /(\mathrm{Ag}+\mathrm{Cu})$ ratio 
Table 1 Composition results (atomic ratio) of $\left(\mathrm{Cu}_{1-x} \mathrm{Ag}_{x}\right)_{2} \mathrm{ZnSn}(\mathrm{S}, \mathrm{Se})_{4}$ solar cells with $x$ from 0 to $6 \%$

\begin{tabular}{lllllllllrr}
\hline Sample & $\mathrm{Ag} /(\mathrm{Ag}+\mathrm{Cu})$ & $\mathrm{Cu}$ & $\mathrm{Ag}$ & $\mathrm{Zn}$ & $\mathrm{Sn}$ & $\mathrm{S}$ & $\mathrm{Se}$ & $\mathrm{Ag} /(\mathrm{Cu}+\mathrm{Ag})$ & $(\mathrm{Ag}+\mathrm{Cu}) /(\mathrm{Zn}+\mathrm{Sn})$ & $\mathrm{Zn} / \mathrm{Sn}$ \\
\hline F0 & $0 \%$ & 20.82 & 0.00 & 12.75 & 13.10 & 2.25 & 51.09 & 0.00 & 0.81 & 0.97 \\
F2 & $2 \%$ & 17.35 & 0.46 & 12.03 & 11.13 & 6.58 & 52.44 & 0.03 & 0.77 \\
F3 & $3 \%$ & 18.07 & 0.78 & 11.51 & 12.92 & 4.67 & 52.05 & 0.04 & 0.77 & 0.80 \\
F4 & $4 \%$ & 20.01 & 1.10 & 12.45 & 13.82 & 3.79 & 48.84 & 0.05 & 0.80 \\
F5 & $5 \%$ & 19.49 & 1.27 & 12.72 & 13.13 & 4.52 & 48.86 & 0.06 & 0.90 \\
F6 & $6 \%$ & 19.31 & 1.49 & 12.25 & 12.99 & 5.91 & 48.05 & 0.07 & 0.92 & 0.94 \\
\hline
\end{tabular}

$(x=4 \%)$. More importantly, with increasing the $\mathrm{Ag} /(\mathrm{Ag}+\mathrm{Cu})$ ratio from 0 to $6 \%$, the $V_{\text {oc,def }}$ was gradually decreased and the band tailing was suppressed.

\section{Experimental details}

\subsection{Materials}

Cu (99.9\%, Aladdin), Ag (99.9\%, Aladdin), Zn (99.9\%, Aladdin), Sn (99.8\%, Alfa Aesar), S (99.9\%, Aladdin) and Se (99\%, Alfa Aesar) powders were used as received without further purification. 1,2-Ethanedithiol $\left(\mathrm{HSCH}_{2} \mathrm{CH}_{2} \mathrm{SH}, \mathrm{AR}\right)$, 1,2-ethylenediamine $\left(\mathrm{H}_{2} \mathrm{NCH}_{2} \mathrm{CH}_{2} \mathrm{NH}_{2}, \mathrm{AR}\right)$, thioglycolic acid $\left(\mathrm{HSCH}_{2} \mathrm{COOH}\right.$, 99\%), ethanolamine $\left(\mathrm{HOCH}_{2} \mathrm{CH}_{2} \mathrm{NH}_{2}, \mathrm{AR}\right)$, 2-methoxyethanol (AR), ammonium hydroxide $\left(\mathrm{NH}_{4} \mathrm{OH}, 25 \%\right)$, cadmium sulfate (AR) and thiourea (AR) were all purchased from Aladdin.
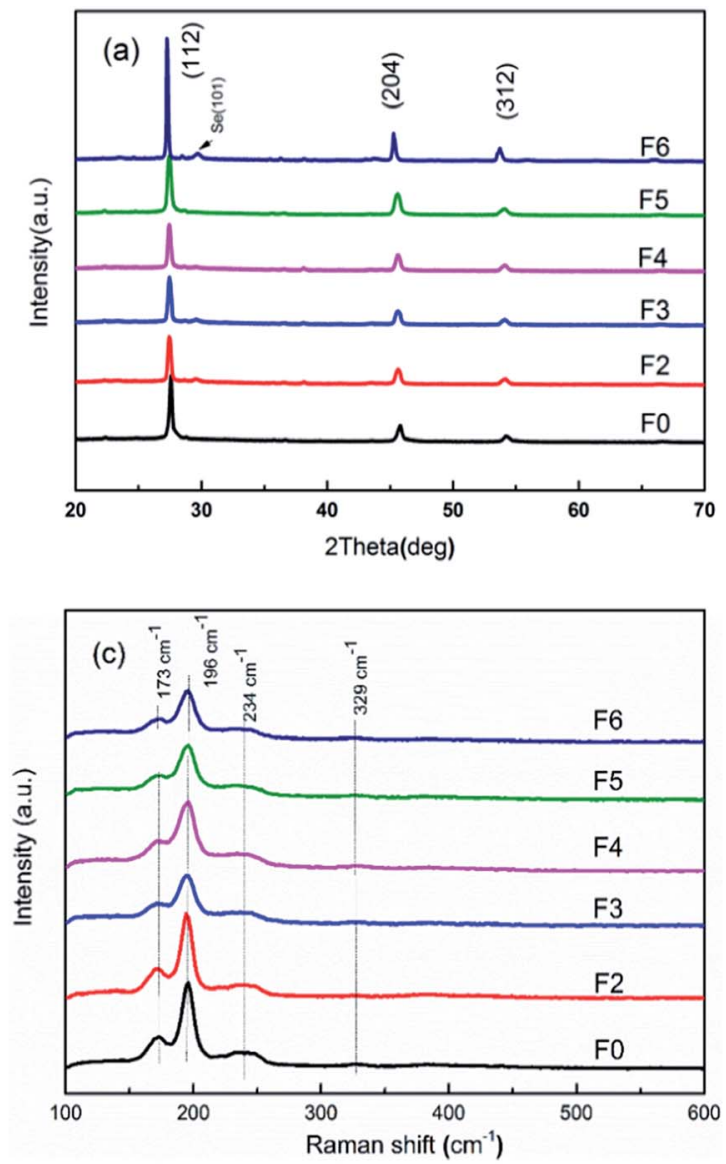

\subsection{Preparation of Mo foils}

To obtain clean surface of Mo foil (0.02 mm thick, 99.95\% purity), Mo foil was potentiostatically polished at $8 \mathrm{~V}$ (vs. Ag/ $\mathrm{AgCl}$ ) at room temperature for $1 \mathrm{~min}$ in $87.5 \mathrm{~mL}$ methanol and $12.5 \mathrm{~mL}$ sulfuric acid mixed solution. And then the Mo foil was rinsed successively in acetone, ethanol, and deionized water for $30 \mathrm{~min}$ by ultrasonic cleaning.

\subsection{Formation of CZTSSe precursor solution}

To prepare CAZTSSe precursor solution, $1.10 \mathrm{mmol} \mathrm{Cu}$ (or $\mathrm{Cu}$ and $\mathrm{Ag}$ ), $0.75 \mathrm{mmol} \mathrm{Zn}, 0.72 \mathrm{mmol} \mathrm{Sn}, 0.30 \mathrm{mmol} \mathrm{Se}$, and $2.60 \mathrm{mmol} \mathrm{S}$ were added into a $25 \mathrm{~mL}$ round flask. Then, $0.5 \mathrm{~mL}$ of 1,2-ethanedithiol and $5 \mathrm{~mL}$ of 1,2-ethylenediamine were mixed into the flask. Afterward, the solution was magnetically stirred until all the
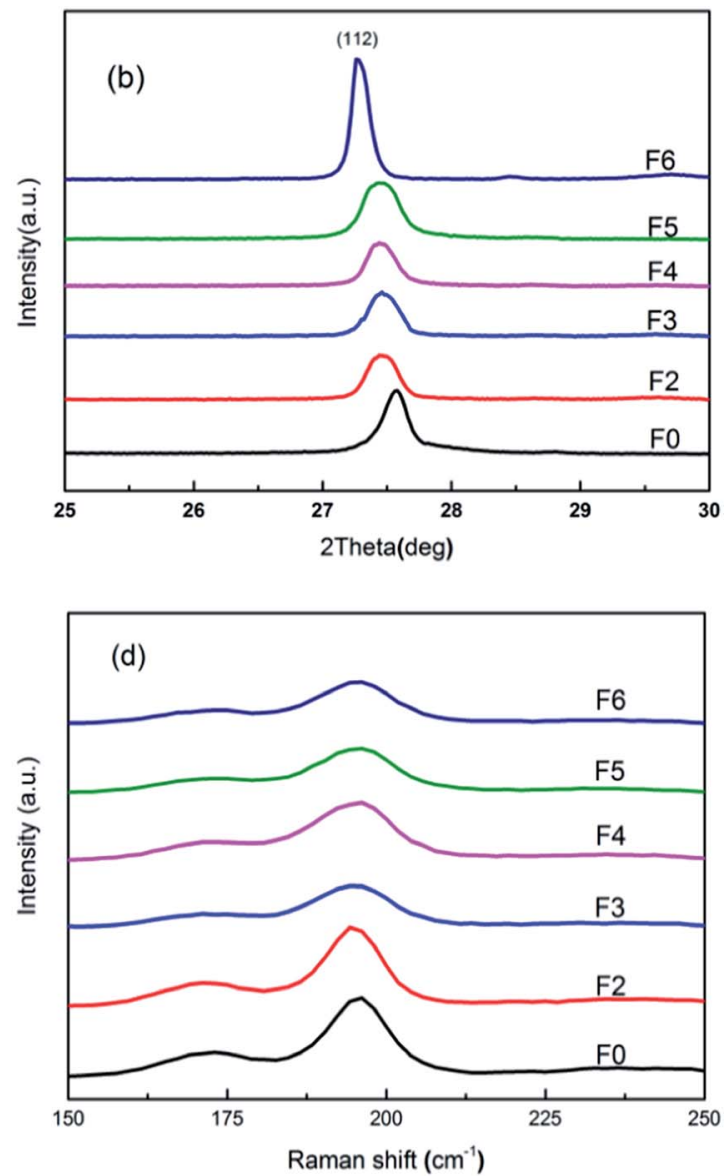

Fig. 1 (a) X-ray diffraction patterns, (b) enlarged shifts of (112) peaks, (c) Raman spectra, and (d) enlarged view of Raman shift for the selenized $\left(\mathrm{Cu}_{1-x} \mathrm{Ag}_{x}\right)_{2} \mathrm{ZnSn}(\mathrm{S}, \mathrm{Se})_{4}$ thin films with different ratios of $\mathrm{Ag} /(\mathrm{Ag}+\mathrm{Cu})$ on the glass substrates. 

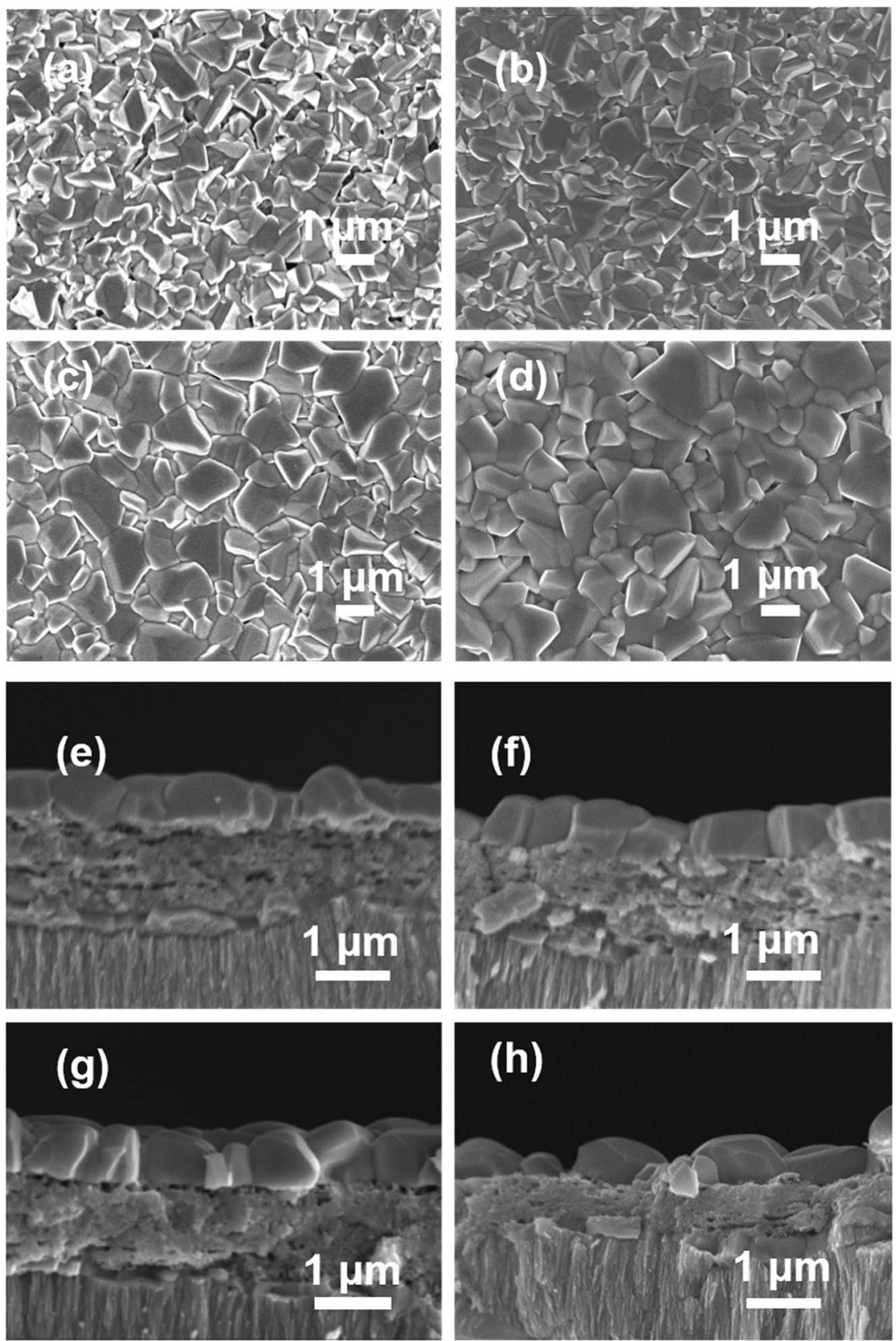

Fig. 2 Typical surface and cross-section SEM images of the CAZTSSe thin films on the Mo foils with different ratios of Ag/(Cu + Ag): (a) and (e) FO; (b) and (f) F2; (c) and (g) F4; (d) and (h) F6.

solids had dissolved. After that, $1 \mathrm{~mL}$ stabilizer solution $(0.25 \mathrm{~mL}$ ethanolamine, $0.25 \mathrm{~mL}$ thioglycolic acid, $0.5 \mathrm{~mL}$ 2-methoxyethanol) was mixed into the flask. Then, the solution was magnetically stirred to keep the solution stable. The ratio of the starting materials followed the target of $\mathrm{Cu}$-poor and $\mathrm{Zn}$-rich stoichiometry, i.e., $(\mathrm{Ag}+\mathrm{Cu}) /(\mathrm{Zn}+\mathrm{Sn})=0.75$ and $\mathrm{Zn} / \mathrm{Sn}=1.04$. To investigate the influence on the performance of the flexible solar cells, we prepared 6 precursor solutions with different $\mathrm{Ag}$ doping concentrations, i.e., $x=\mathrm{Ag} /(\mathrm{Cu}+\mathrm{Ag})=0,2,3,4,5$ and $6 \%$.

\subsection{Fabrication of Ag-doped CZTSSe films and solar cells}

The CZTSSe and CAZTSSe precursor thin films were prepared by spin-coating the precursor solution on Mo foils at $2800 \mathrm{rpm}$ for
$30 \mathrm{~s}$, followed by sintering on a $350{ }^{\circ} \mathrm{C}$ hot plate for $2 \mathrm{~min}$. This procedure was repeated 9 times until the precursor films had a targeted thickness $(\sim 1.5 \mu \mathrm{m})$. All the operations mentioned about were performed in an argon-filled glovebox. The asprepared CAZTSSe thin films were selenized in a round graphite box with $600 \mathrm{mg}$ of Se at $480{ }^{\circ} \mathrm{C}$ for $25 \mathrm{~min}$. These films were symbolled as $\mathrm{F} x$, which means film with different $\mathrm{Ag}$ contents $x \%, x \%=\mathrm{Ag} /(\mathrm{Cu}+\mathrm{Ag})=0,2,3,4,5$ and $6 \%$, respectively. CAZTSSe thin films solar cells with the structure of $\mathrm{Ag} / \mathrm{ITO} / \mathrm{i}-\mathrm{ZnO} / \mathrm{CdS} / \mathrm{CAZTSSe} / \mathrm{Mo}$ foil were fabricated according to the detailed fabrication process. First, CdS buffer layer $(\sim 40$ $\mathrm{nm}$ ) was deposited on the CAZTSSe thin film using a chemical bath approach, then i-ZnO $(\sim 50 \mathrm{~nm})$ and ITO $(\sim 200 \mathrm{~nm})$ layers 
were deposited on the CdS layer by magnetron sputtering. Then, $500 \mathrm{~nm} \mathrm{Ag}$ grid electrodes were thermally evaporated as the front contact. These solar cells were symbolled as $\mathrm{C} x$, which means solar cell with different Ag contents $x \%, x \%=\mathrm{Ag} /(\mathrm{Cu}+$ $\mathrm{Ag})=0,2,3,4,5$ and $6 \%$, respectively. Finally, all CAZTSSe devices with an active area of $0.21 \mathrm{~cm}^{2}$, which is about $91 \%$ of the total device area, were separated by mechanical scribing. No antireflection layer was deposited.

\subsection{Characterizations}

The scanning electron microscope (SEM) images were obtained using a Nova Nano SEM 450 with an energy dispersive X-ray analyzer (FEI, Nova Nano SEM 450/EDX). The X-ray diffraction (XRD) patterns were collected by a Rigaku Smartlab (Cu target, $40 \mathrm{kV}, 30 \mathrm{~mA}$ ). Raman spectra were recorded by Renishaw inVia Raman microscope using a $532 \mathrm{~nm}$ excitation wavelength. Photoluminescence measurements were recorded at room temperature using an $808 \mathrm{~nm}$ solid state laser with a filter of $850 \mathrm{~nm}$. Current density-voltage $(J-V)$ curves were recorded under the standard AM1.5 illumination $\left(100 \mathrm{~mW} \mathrm{~cm}{ }^{-2}\right)$ with a Keithley 2400 source meter. The external quantum efficiency (EQE) spectra were obtained using a CROWNTECH CT-SC-T QE system equipped with a $150 \mathrm{~W}$ xenon light source. The capacitance-voltage $(C-V)$ curves were measured by a semiconductor characterization system (4200-SCS: Keithley, USA).

\section{Results and discussions}

Table 1 shows the composition results (atomic ratio) of $\left(\mathrm{Cu}_{1-x} \mathrm{Ag}_{x}\right)_{2} \mathrm{ZnSn}(\mathrm{S}, \mathrm{Se})_{4}$ solar cell with $x(0-6 \%)$ by energydispersive X-ray spectrometry (EDX). The content of Ag varied from $0 \%$ to $1.49 \%$ when the $x$ is changed from $0 \%$ to $6 \%$, which indicates that the additional $\mathrm{Ag}$ can be incorporated into the final CAZTSSe films and can be controlled by the precursor solution. It can be seen from Table 1 that, as the $\mathrm{Ag}$ concentration increased from 0.46 to $1.49 \%$, the amount of Sn in the final CAZTSSe films was enhanced from $11.13 \%$ to $12.99 \%$, which indicates that the incorporation of $\mathrm{Ag}$ can reduce the $\mathrm{Sn}$ loss during the selenization process.
Fig. 1(a) shows the XRD patterns of the CAZTSSe thin films with $x$ from 0 to $6 \%$. It can be seen that, except for the residual selenium peak ((101), $\left.2 \theta=29.66^{\circ}\right)$, all the diffraction peaks from (112), (204), and (312) planes are consistent with the kesterite-type tetragonal phase. Fig. 1(b) shows the enlarged views of main (112) diffraction peak. The peaks shift to lower $2 \theta$ with $x$ from 0 to $6 \%$, indicating that $\mathrm{Ag}^{+}$was successfully incorporated into the host lattice of CZTSSe. These results are in accordance with previous reports. ${ }^{15,19,20}$ The XRD patterns of some binary and ternary selenide, such as $\mathrm{ZnSe}$, and $\mathrm{Cu}_{2} \mathrm{SnSe}_{3}$, are similar to that of CZTSSe, so it is difficult to identify the phase purity of CZTSSe films just by XRD characterization. The Raman spectra can be used as an effective tool to differentiate these impurities. Fig. 1(c) shows Raman spectra of the selenized CZTSSe and CAZTSSe films. Under the selenization condition, the amount of Se is much larger than $\mathrm{S}$, as illustrated in Table 1. As a result, a weak peak appears around $329 \mathrm{~cm}^{-1}$ caused corresponding to the kesterite CZTS phase. More remarkable peaks in the vicinity of 173,196 , and $234 \mathrm{~cm}^{-1}$ can be attributed to kesterite CZTSe phase. ${ }^{21}$ From the Fig. 1(d), one can see that, the most intense peak around $197 \mathrm{~cm}^{-1}$ shows weak sensitivity to the Ag substitution. This is because this vibration mode is a symmetric mode without involving any cation motion..$^{22}$ That is in accordance with the observations in the XRD results.

Fig. 2 shows the surface and cross-section SEM images of the CAZTSSe thin films on the Mo foils with $x$ ranging from 0 to $6 \%$. It can be seen from Fig. 2(b-d) that, the incorporation of small amount of $\mathrm{Ag}^{+}$significantly improves the film surface morphology. As $x$ increased from 0 to $4 \%$, the voids and holes are obviously reduced, and the sizes of grains are clearly increased, and the grains are more densely packed. However, the surface of $\mathrm{F} 6$ is rough with some intergranular voids. According to the cross-section SEM images, the CAZTSSe absorber exhibits a typical tri-layer structure, i.e., a largegrained layer on top, a fine-grain layer in the middle, and a large-grained bottom layer near Mo foil. From the crosssection SEM images of the sample F6, we can see a slight reduction in the thickness of fine-grain layer and some voids generation on the surface.
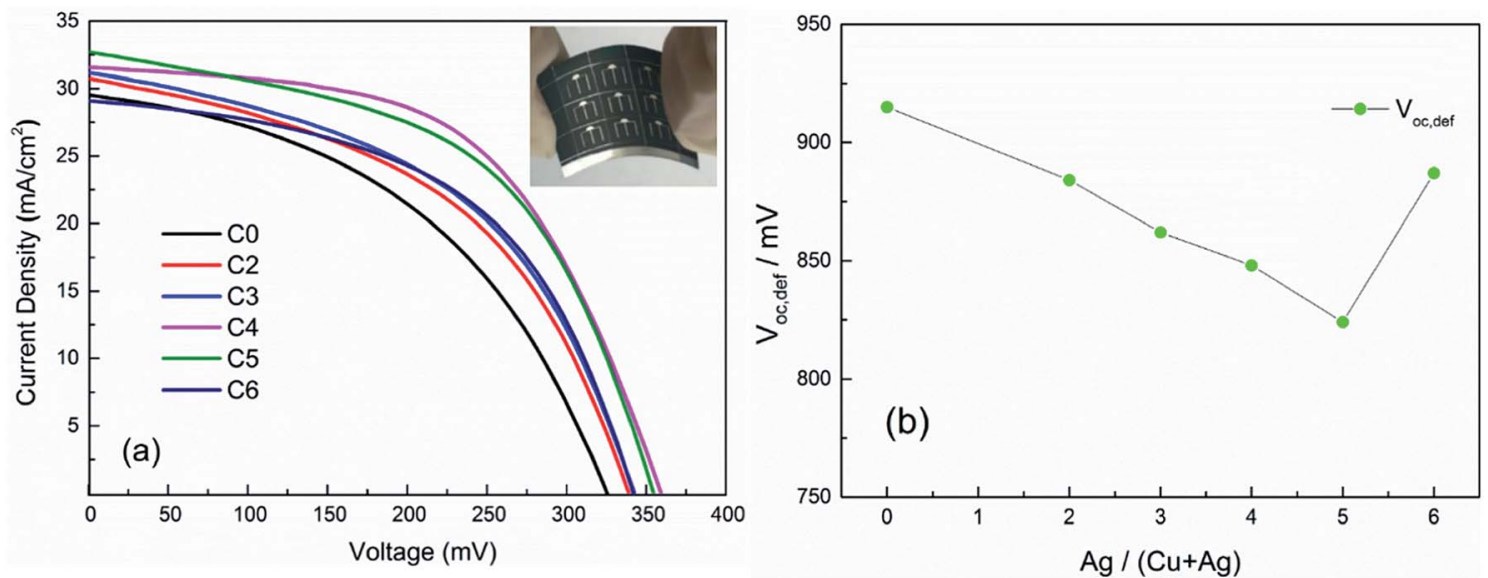

Fig. 3 (a) Current-voltage curves of the $\left(\mathrm{Cu}_{1-x} \mathrm{Ag}{ }_{x}\right)_{2} \mathrm{ZnSn}(\mathrm{S}, \mathrm{Se})_{4}$ devices with different ratios of $\mathrm{Ag} /(\mathrm{Ag}+\mathrm{Cu})$ under AM $1.5 \mathrm{G}$ illumination. The inset shows the image of the flexible solar cell. (b) $V_{o c, \text { def }}$ of the $\left(\mathrm{Cu}_{1-x} \mathrm{Ag}_{x}\right)_{2} \mathrm{ZnSn}(\mathrm{S}, \mathrm{Se})_{4}$ devices with different ratios of $\mathrm{Ag} /(\mathrm{Ag}+\mathrm{Cu})$. 
Table 2 Detailed device parameters of $\left(\mathrm{Cu}_{1-x} \mathrm{Ag}{ }_{x}\right)_{2} \mathrm{ZnSn}(\mathrm{S}, \mathrm{Se})_{4}$ solar cells with different ratios of $\mathrm{Ag} /(\mathrm{Ag}+\mathrm{Cu})$

\begin{tabular}{llllll}
\hline Sample & $\mathrm{Ag} /(\mathrm{Ag}+\mathrm{Cu})$ & PCE $(\%)$ & $V_{\text {oc }}(\mathrm{mV})$ & $J_{\text {sc }}\left(\mathrm{mA} \mathrm{cm}^{-2}\right)$ & $\mathrm{FF}(\%)$ \\
\hline C0 & $0 \%$ & 4.34 & 324 & 30.42 & 43.95 \\
$\mathrm{C} 2$ & $2 \%$ & 4.90 & 337 & 30.64 & 47.32 \\
$\mathrm{C} 3$ & $3 \%$ & 5.09 & 340 & 31.09 & 48.09 \\
$\mathrm{C} 4$ & $4 \%$ & 6.24 & 358 & 31.51 & 55.28 \\
$\mathrm{C} 5$ & $5 \%$ & 6.01 & 353 & 32.65 & 52.06 \\
$\mathrm{C} 6$ & $6 \%$ & 5.20 & 339 & 29.22 & 50.17
\end{tabular}

To further evaluate the impact of Ag substitution on flexible CAZTSSe solar cell performance, the current-voltage $(J-V)$ curves of CAZTSSe solar cells fabricated with the same architecture are presented in Fig. 3(a). With $x$ increasing from 0 to $4 \%$, the PCE of the CAZTSSe devices on Mo foils increases from $4.34 \%(\mathrm{C} 0)$ to $6.24 \%$ (C4). As $x$ further increases to $6 \%$, the PCE drops to $5.01 \%$ (C6). Table 2 displays the corresponding device parameters of the samples. From Fig. 3(a) and Table 2, one can see that the photovoltaic parameters PCE, $V_{\mathrm{oc}}$, the fill factor $(\mathrm{FF})$ achieve the optimized value with $\mathrm{Ag}$ content of $4 \%$. Compared with the pure CZTSSe solar cell (C0), the $V_{\text {oc }}$, short-circuit
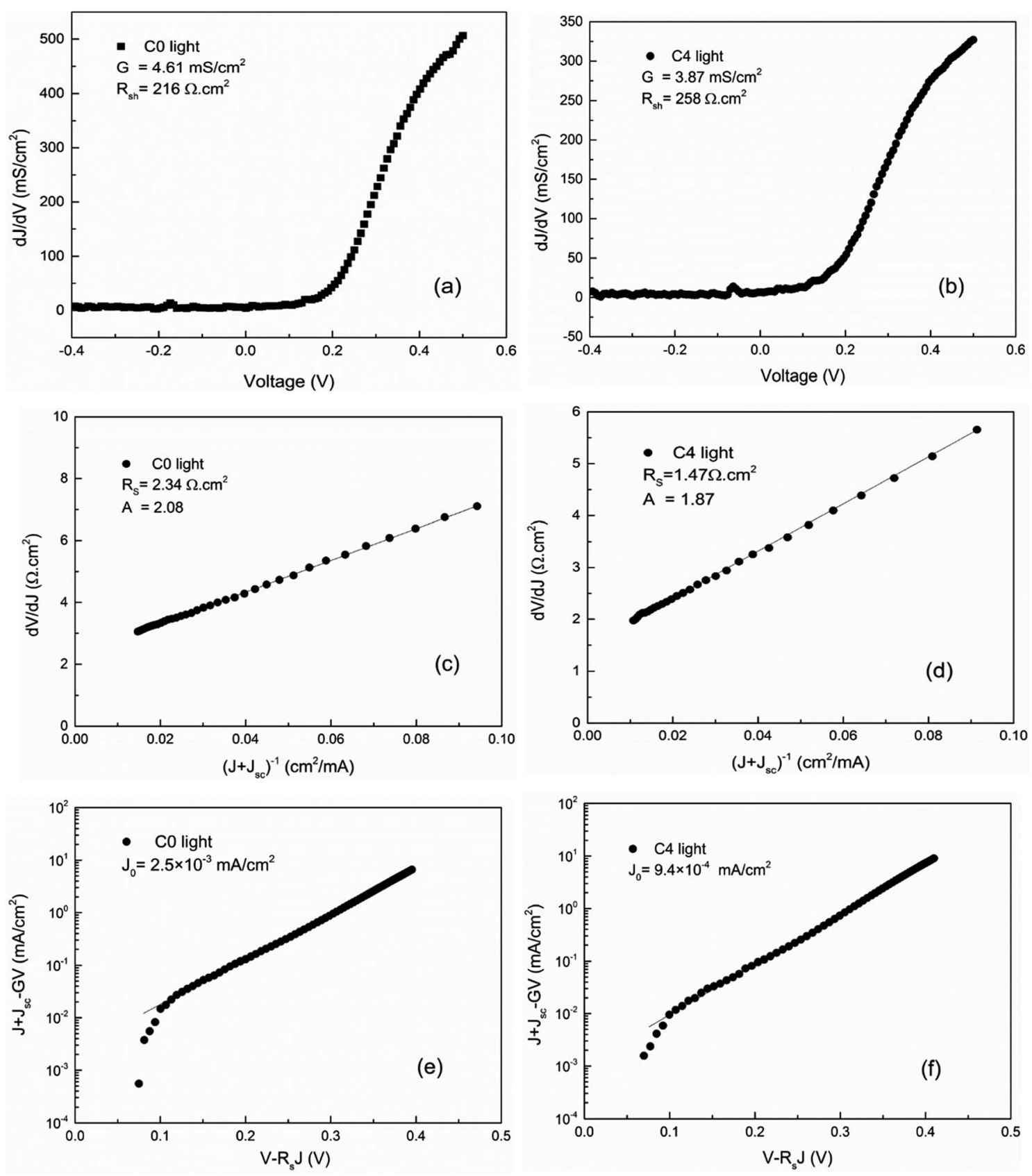

Fig. 4 Plot of $d J / d V$ vs. $V$ repainted from the standard light $J-V$ curve for CAZTSSe samples (a) C0, (b) C4, where $G$ value was extracted from the plateau value; Plot of $d V / d J$ vs. $\left(J+J_{s c}\right)^{-1}$ for CAZTSSe samples (c) CO, (d) C4, where $R$ and $A$ value were evaluated from the intercept and slope of the linear region of the curve, respectively; semi-logarithmic plot of $J+J_{\text {sc }}-G V v s . V-R J$ for CAZTSSe samples (e) C0, (f) C4, where $J_{0}$ value was obtained from the intercept of the curve. 


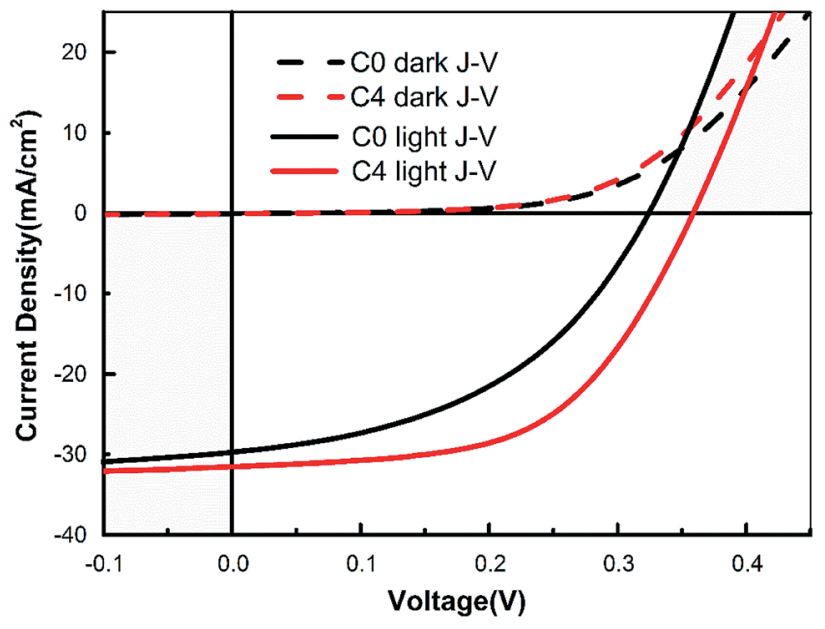

Fig. 5 Current-voltage curves of the best flexible CAZTSSe cell and the pure CZTSSe flexible reference cell.

current density $\left(J_{\mathrm{sc}}\right)$, and $\mathrm{FF}$ values of the champion CAZTSSe solar cell (C4) are increased of $34 \mathrm{mV}, 1.09 \mathrm{~mA} \mathrm{~cm}{ }^{-2}$, and $11.33 \%$, respectively. Fig. $3(\mathrm{~b})$ displays the $V_{\mathrm{oc} \text {,def }}$ of all the CAZTSSe devices. Interestingly, a severe $V_{\mathrm{oc}, \text { def }}$ also decreases from 915 to $824 \mathrm{mV}$ when $x$ varies from 0 to $5 \%$. This result indicates that the $\mathrm{Cu}_{\mathrm{Zn}}$ antisite defects, a primary cause of $V_{\mathrm{oc}}$ loss in CZTSSe device, are obviously suppressed in the CAZTSSe samples with the optimal Ag doping level.

Fig. 4 shows the performance of the shunt conductance $\left(G_{\mathrm{sh}}\right)$, shunt resistance $\left(R_{\mathrm{sh}}\right)$, series resistance $\left(R_{\mathrm{s}}\right)$, diode ideality factor $(A)$, and reverse saturation current density $\left(J_{0}\right)$ of the samples C4 and C0. As we all known, the relationship between the $V_{\mathrm{oc}}$ and these parameters can be characterized using the following equation: ${ }^{23}$

$$
G_{\mathrm{sh}} V_{\mathrm{oc}}=J_{\mathrm{sc}}-J_{0}\left(\mathrm{e}^{\frac{q V_{\mathrm{oc}}}{n K T}}-1\right)
$$

The reduction of the $G_{\mathrm{sh}}$ and $J_{0}$ can improve the value of the $V_{\mathrm{oc}}$. In addition, $J_{\mathrm{sc}}$ and $\mathrm{FF}$ are also related to these parameters. Compared to sample $\mathrm{C} 0$, the value $A$ of sample $\mathrm{C} 4$ is greatly reduced, indicating that Ag-doping can effectively alleviate the serious recombination occurred at the interface..$^{24,25}$ Meanwhile, compared with sample $\mathrm{C} 4$, the relatively high value of $J_{0}$ for sample C0 demonstrates that a mass of defects result in the carrier recombination, which will decrease the $V_{\mathrm{oc}}$ and FF. Therefore, incorporating the desired amount of $\mathrm{Ag}^{+}$into CZTSSe can effectively reduce $J_{0}$ and $A$, and the interfaces recombination can be obviously suppressed.

Fig. 5 shows the dark and light $J-V$ curves of samples $\mathrm{C} 0$ and C4. The crossover point between the dark and light $J-V$ curves for sample C4, i.e., $22 \mathrm{~mA} \mathrm{~cm} \mathrm{~cm}^{-2}$, is much higher than that of sample $\mathrm{C} 0$, i.e., $8 \mathrm{~mA} \mathrm{~cm}{ }^{-2}$. The crossover phenomena are mainly caused by a high density of acceptor-type defects and by the band alignment between the buffer and absorber layers. ${ }^{26-28}$ The higher value of the crossover point for CAZTSSe device implies a reduced electron supply barrier at the buffer/absorber interface, which might originate from the low density of deep acceptors close to the hetero-interface. ${ }^{20}$

Fig. 6(a) presents the EQE spectra of the CAZTSSe devices with $x$ from 0 to $6 \%$. All samples show distinct spectral response. Compared with sample $\mathrm{C}$, all samples with $\mathrm{Ag}$ incorporations show a higher photo-response in the visible and near-infrared wavelength. It should be noted that sample $\mathrm{C} 4$ shows the highest value of $\mathrm{EQE}$, which is over $80 \%$ in the wavelength ranging from 540 to $790 \mathrm{~nm}$, indicating a lower recombination rate of photo-generated carriers happened in the CZTSSe bulk and interface. Interestingly, the phenomenon of the low-lying decay below $520 \mathrm{~nm}$ has been dramatically improved compared with other experimental results by optimizing the process of CdS buffer layer. ${ }^{18-20}$ In practice, the loss of absorption results from the thicker of CdS layer. Besides, the $E_{\mathrm{g}}$ of the CAZTSSe thin film can be extracted from the data near the band edge by plotting $[E \times \ln (1-$ $\mathrm{EQE})]^{2}$ versus $E{ }^{26}$ as depicted in Fig. 6(b). The summary of the detailed device parameters including $V_{\text {oc,def }}\left(E_{\mathrm{g}} / q-V_{\mathrm{oc}}\right)$ is also presented in Table 3. Accordingly, when the $\mathrm{Ag}$ content increases from 0 to $5 \%$, the $E_{\mathrm{g}}$ values of CAZTSSe thin films decreases from $1.24 \mathrm{eV}$ to a minimum of $1.12 \mathrm{eV}$ and then increase to $1.23 \mathrm{eV}$ for $\mathrm{Ag}$ content of $6 \%$. When the $\mathrm{Ag}$ content increases to $5 \%$, the $V_{\text {oc,def }}$ of CAZTSSe solar cells decrease to a minimum value, and when the $\mathrm{Ag}$ concentration is increased to $6 \%$, the $V_{\text {oc,def }}$ increases again. It can be seen that, the band gap of the CAZTSSe absorber can be adjusted and the $V_{\text {oc,def }}$ of the flexible CAZTSSe solar cells can be ameliorated by incorporating the desired amount of $\mathrm{Ag}^{+}$.
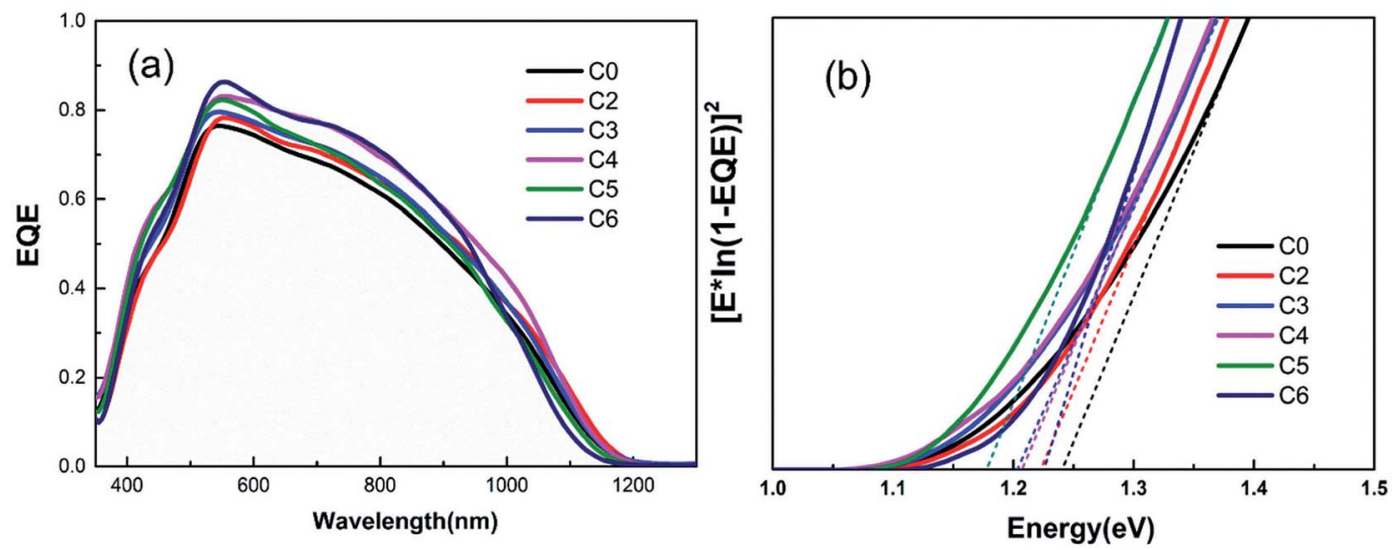

Fig. 6 (a) Relative EQE spectra of the $\left(\mathrm{Cu}_{1-x} \mathrm{Ag}_{x}\right)_{2} \mathrm{ZnSnSe}{ }_{4}$ thin film solar cells. (b) Band gap of the different cells determined from EQE data. 
Table 3 Summary of detailed device parameters for $\left(\mathrm{Cu}_{1-x} \mathrm{Ag}_{x}\right)_{2} \mathrm{ZnSnSe}{ }_{4}$ solar cells with different Ag doping levels

\begin{tabular}{|c|c|c|c|c|c|c|c|c|}
\hline Sample & $J_{\mathrm{sc}}\left(\mathrm{mA} \mathrm{cm}{ }^{-2}\right)$ & $V_{\mathrm{oc}}(\mathrm{mV})$ & $E_{\mathrm{g}}(\mathrm{eV})$ & $E_{\mathrm{g}} / q-V_{\mathrm{oc}}(\mathrm{mV})$ & PL (eV) & $E_{\mathrm{g}}-\mathrm{PL}(\mathrm{eV})$ & $W_{\mathrm{d}}(\mu \mathrm{m})$ & $N_{C-V}\left(\mathrm{~cm}^{-3}\right)$ \\
\hline $\mathrm{C} 0$ & 30.42 & 324 & 1.239 & 915 & 1.067 & 0.172 & 0.171 & $9.05 \times 10^{9}$ \\
\hline $\mathrm{C} 2$ & 30.64 & 337 & 1.221 & 884 & 1.053 & 0.168 & 0.215 & $8.52 \times 10^{9}$ \\
\hline $\mathrm{C} 4$ & 31.51 & 358 & 1.206 & 848 & 1.046 & 0.160 & 0.299 & $6.68 \times 10^{9}$ \\
\hline C5 & 32.65 & 353 & 1.177 & 824 & 1.028 & 0.149 & 0.262 & $7.55 \times 10^{9}$ \\
\hline C6 & 29.22 & 339 & 1.225 & 887 & 1.052 & 0.161 & 0.202 & $8.62 \times 10^{9}$ \\
\hline
\end{tabular}

Fig. 7(a) depicts the normalized photoluminescence (PL) spectra as a function of the $\mathrm{Ag} /(\mathrm{Ag}+\mathrm{Cu})$ in the CAZTSSe thin films. PL spectroscopy is a useful technique to estimate the band gap of the surface layer (depth below $50 \mathrm{~nm}$ ) for direct band gap materials, and the results are illustrated in Table 3 and Fig. 7(b). It can be seen that the room-temperature PL peak position shifts to lower energies, i.e., it decreases from 1.07 to $1.03 \mathrm{eV}$ as $\mathrm{Ag}$ content increased from 0 to $5 \%$, and it shifts to a higher value $(1.05 \mathrm{eV})$ when the $\mathrm{Ag}$ content is increased to $6 \%$. This observation suggests that there is a turning point in the curve of $E_{\mathrm{g}} v s$. Ag concentration, which explains the controversial observation of previous works, i.e., it is reported in ref. 17, 18 and 20 that the band gap increases with the ratio of $\mathrm{Ag} /(\mathrm{Ag}+$ $\mathrm{Cu})$, but it is found in ref. 19 that the band gap decreases with the ratio of $\mathrm{Ag} /(\mathrm{Ag}+\mathrm{Cu})$. Besides, the results are in good agreement with the $E_{\mathrm{g}}$ obtained from the EQE. It can be seen from Fig. $7(\mathrm{c})$ that, as the $\mathrm{Ag}$ concentration $x$ is increased from 0 to $5 \%$, the energy differences between the $E_{\mathrm{g}}$ and the PL peak position is decreased from 172 to $149 \mathrm{meV}$. The results indicate that the band tailing can be effectively reduced by introducing appropriate $\mathrm{Ag}$ concentration into CZTSSe.

In order to find out the reason of the different performances, the depletion region width $\left(W_{\mathrm{d}}\right)$ and charge carrier density $\left(N_{C-}\right.$ $v$ ) of the samples were measured by a $C-V$ method at a reverse bias from 0 to $-1 \mathrm{~V}$ at $300 \mathrm{~K}$, and the results are depicted in Fig. 8(a) and (b). The detailed values of $W_{\mathrm{d}}$ and $N_{C-V}$ for the CAZTSSe devices with different $x$ are shown in Table 3 . It can be seen that, the $N_{C-V}$ decreases from $9.05 \times 10^{16}$ to $6.68 \times 10^{16}$
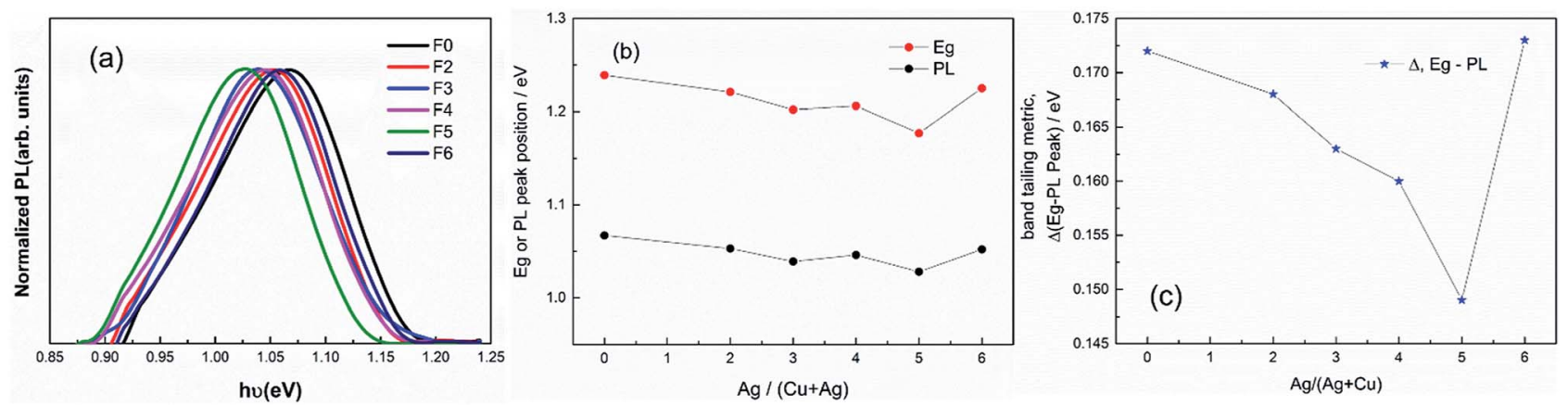

Fig. 7 (a) Normalized PL spectra of $\left(\mathrm{Cu}_{1-x} \mathrm{Ag}_{x}\right)_{2} \mathrm{ZnSnSe} \mathrm{H}_{4}$ thin films with different $x\left(x=0-6 \%\right.$ ). (b) $E_{\mathrm{g}}$ values, room-temperature PL peak positions and $V_{\mathrm{oc}, \text { def }}$ as a function of $\mathrm{Ag} /(\mathrm{Ag}+\mathrm{Cu}$ ). (c) Energy differences between the room-temperature band gap and PL peak position with different $x(x$ $=0-6 \%$.
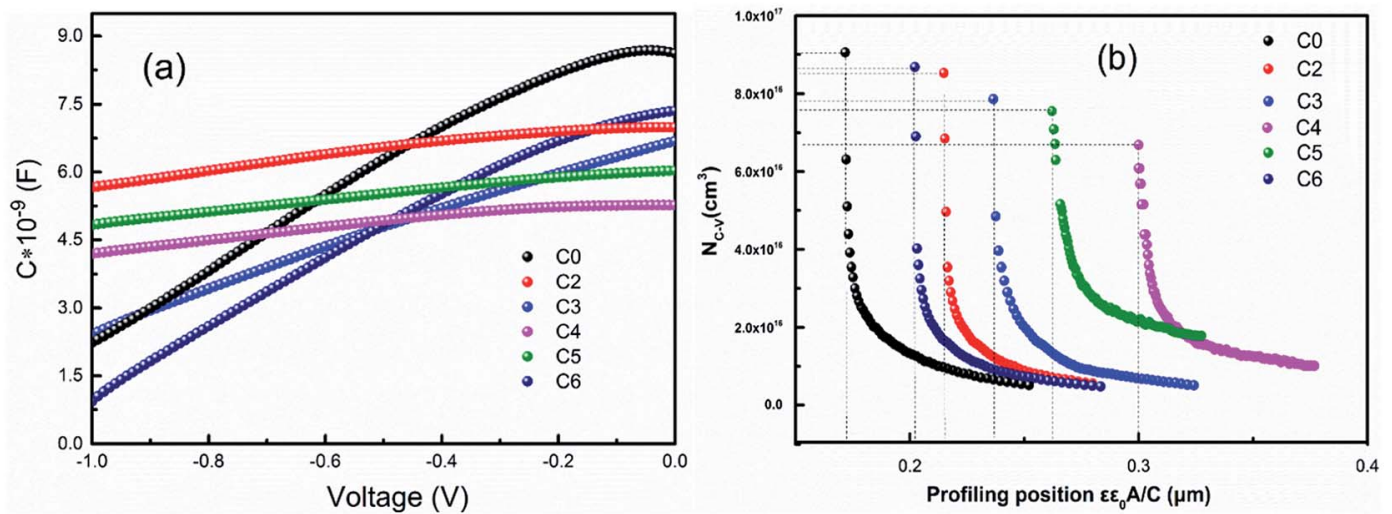

Fig. 8 (a) Capacitance-voltage $(C-V)$ curves of $\left(\mathrm{Cu}_{1-x} \mathrm{Ag}_{x}\right)_{2} \mathrm{ZnSnSe} e_{4}$ thin film solar cells with different $x$. (b) Space-charge density and depletion width derived from $C-V$ curves. These results were obtained under reverse bias from -1.0 to $0 \mathrm{~V}$ at $300 \mathrm{~K}$. 
$\mathrm{cm}^{-3}$ when $x$ increases from 0 to $4 \%$, and the $N_{C-V}$ is increased to $8.62 \times 10^{16} \mathrm{~cm}^{-3}$ when $x$ is further increased to $6 \%$. This indicates that the incorporation of $\mathrm{Ag}$ will greatly influence the $N_{C-V}$ of the absorber and influence the $W_{\mathrm{d}}$ of the CAZTSSe devices. With $x$ varying from 0 to $4 \%$, the $W_{\mathrm{d}}$ of the devices increases from $0.17 \mu \mathrm{m}$ to the maximum value of $0.30 \mu \mathrm{m}$. However, as the $\mathrm{Ag}$ content increased from 4 to $6 \%$, the $W_{\mathrm{d}}$ of the device decreases to $0.20 \mu \mathrm{m}$. It is well known that $W_{\mathrm{d}}$ can influence the charge separation and collection, and finally affect the conductivity of solar cells. ${ }^{29}$ A narrow depletion region width is harmful for the effective collection of the photo-generated charge carrier, especially for the long wavelength region close to the band edge, and can result in increased interface recombination or tunneling recombination, thus leading to a significant $V_{\text {oc }}$ loss. Our work suggests that the substitution of $\mathrm{Cu}^{+}$ with $\mathrm{Ag}^{+}$in CZTSSe thin film solar cell can significantly increase the $W_{\mathrm{d}}$ value for the optimal $\mathrm{Ag}$ composition $(x=4 \%)$. As a result, the $V_{\mathrm{oc}}$ and $\mathrm{FF}$ are successfully increased from $324 \mathrm{mV}$, $43.95 \%$ to $358 \mathrm{mV}, 55.28 \%$, respectively. The above results prove that both of the charge carrier concentration and $W_{\mathrm{d}}$ are very sensitive to the relative content of $\mathrm{Ag}^{+}$, and the optimal incorporation of $\mathrm{Ag}(x=4 \%)$ can significantly increases the value of $W_{\mathrm{d}}$.

\section{Conclusion}

In conclusion, a safe and convenient solution method has been developed to produce CAZTSSe thin films on Mo foils. The small quantity of $\mathrm{Ag}^{+}$incorporation can be easily controlled by adjusting the chemical composition of the elemental powders. The band gap of CAZTSSe thin films can be tuned to a minimum value when the $\mathrm{Ag}$ content is increased to $5 \%$, and the band gap increases when the $\mathrm{Ag}$ concentration is further increased to $6 \%$. Meanwhile, increasing $\mathrm{Ag}$ content in the absorber will lead to better crystallization of the CZTSSe thin films, and suppressed the recombination at the interfaces. Finally, a conversion efficiency up to $6.24 \%$ is achieved for the flexible CAZTSSe solar cell with $4 \% \mathrm{Ag}$ incorporation. Comparing with the pure flexible CZTSSe solar cell, about $67 \mathrm{mV}$ reduction in voltage deficit occurs as a result of $\mathrm{Ag}$ substitution, which contributes to the improvement of the device performance.

\section{Conflicts of interest}

There are no conflicts to declare.

\section{Acknowledgements}

This work was supported by the National Natural Science Foundation of China (No. 61574038).

\section{References}

1 D. Tiwari, T. Koehler, X. Lin, R. Harniman, I. Griffiths, L. Wang, D. Cherns, R. Klenk and D. J. Fermin, Chem. Mater., 2016, 28, 4991-4997.
2 Y. Yang, G. Wang, W. Zhao, Q. Tian, L. Huang and D. Pan, ACS Appl. Mater. Interfaces, 2015, 7, 460-464.

3 D. B. Mitzi, O. Gunawan, T. K. Todorov and D. A. R. Barkhouse, Philos. Trans. R. Soc., A, 2013, 371, 20110432.

4 F. Jiang, S. Ikeda, T. Harada and M. Matsumura, Adv. Energy Mater., 2014, 4, 1301381.

5 D. B. Mitzi, O. Gunawan, T. K. Todorov, K. Wang and S. Guha, Sol. Energy Mater. Sol. Cells, 2011, 95, 1421-1436.

6 G. Wang, W. Zhao, Y. Cui, Q. Tian, S. Gao, L. Huang and D. Pan, ACS Appl. Mater. Interfaces, 2013, 5, 10042-10047.

7 W. Wang, M. T. Winkler, O. Gunawan, T. Gokmen, T. K. Todorov, Y. Zhu and D. B. Mitzi, Adv. Energy Mater., 2014, 4, 1301465.

8 K. W. Brew, S. M. McLeod, S. M. Garner and R. Agrawal, Thin Solid Films, 2017, 642, 110-116.

9 L. Dong, S. Cheng, Y. Lai, H. Zhang and H. Jia, Thin Solid Films, 2017, 626, 168-172.

10 J. Xu, Z. Cao, Y. Yang and Z. Xie, J. Mater. Sci.: Mater. Electron., 2014, 26, 726-733.

11 Y. Zhang, Q. Ye, J. Liu, H. Chen, X. He, C. Liao, J. Han, H. Wang, J. Mei and W. Lau, RSC Adv., 2014, 4, 23666-23669.

12 S. Yazici, M. A. Olgar, F. G. Akca, A. Cantas, M. Kurt, G. Aygun, E. Tarhan, E. Yanmaz and L. Ozyuzer, Thin Solid Films, 2015, 589, 563-573.

13 S. Chen, A. Walsh, X.-G. Gong and S.-H. Wei, Adv. Mater., 2013, 25, 1522-1539.

14 J. Li, H. Wang, L. Wu, C. Chen, Z. Zhou, F. Liu, Y. Sun, J. Han and Y. Zhang, ACS Appl. Mater. Interfaces, 2016, 8, 1028310292.

15 D. Shin, B. Saparov and D. B. Mitzi, Adv. Energy Mater., 2017, 7, 1602366.

16 Z.-K. Yuan, S. Chen, H. Xiang, X.-G. Gong, A. Walsh, J.-S. Park, I. Repins and S.-H. Wei, Adv. Funct. Mater., 2015, 25, 6733-6743.

17 T. Gershon, Y. S. Lee, P. Antunez, R. Mankad, S. Singh, D. Bishop, O. Gunawan, M. Hopstaken and R. Haight, Adv. Energy Mater., 2016, 6, 1502468.

18 C. J. Hages, M. J. Koeper and R. Agrawal, Sol. Energy Mater. Sol. Cells, 2016, 145, 342-348.

19 Y. Qi, Q. Tian, Y. Meng, D. Kou, Z. Zhou, W. Zhou and S. Wu, ACS Appl. Mater. Interfaces, 2017, 9, 21243.

20 X. H. Yun Zhao, B. Xu, W. Li, J. Li, J. Li, M. Wang, C. Dong, P. Ju and J. Li, IEEE J. Photovolt., 2017, 7, 874-881.

21 R. Zhang, S. M. Szczepaniak, N. J. Carter, C. A. Handwerker and R. Agrawal, Chem. Mater., 2015, 27, 2114-2120.

22 A. Khare, B. Himmetoglu, M. Johnson, D. J. Norris, M. Cococcioni and E. S. Aydil, J. Appl. Phys., 2012, 111, 3-645.

23 G. Yang, Y.-F. Li, B. Yao, Z.-H. Ding, R. Deng, H.-F. Zhao, L.-G. Zhang and Z.-Z. Zhang, J. Phys. D: Appl. Phys., 2018, 51, 105103.

24 G. Brammertz, M. Buffiere, S. Oueslati, H. ElAnzeery, K. Ben Messaoud, S. Sahayaraj, C. Koeble, M. Meuris and J. Poortmans, Appl. Phys. Lett., 2013, 103, 163904.

25 H. Y. Park, D. G. Moon, J. H. Yun, S. K. Ahn, K. H. Yoon and S. Ahn, Appl. Phys. Lett., 2013, 103, 894-897. 
26 A. Niemegeers, M. Burgelman, R. Herberholz, U. Rau, D. Hariskos and H. W. Schock, Prog. Photovoltaics, 1998, 6, 407-421.

27 M. Burgelman, F. Engelhardt, J. F. Guillemoles, R. Herberholz, M. Igalson, R. Klenk, M. Lampert, T. Meyer, V. Nadenau and A. Niemegeers, Prog. Photovoltaics, 1997, 5, 121-130.
28 S. S. Hegedus and W. N. Shafarman, Prog. Photovoltaics, 2004, 12, 155-176.

29 Y.-F. Qi, D.-X. Kou, W.-H. Zhou, Z.-J. Zhou, Q.-W. Tian, Y.-N. Meng, X.-S. Liu, Z.-L. Du and S.-X. Wu, Energy Environ. Sci., 2017, 10, 2401-2410. 